\title{
Molecular architecture of zinc chelating small molecules that inhibit spliceosome assembly at an early stage
}

\author{
VISHAL PATIL, ${ }^{1}$ JOSH C. CANZONERI, ${ }^{1}$ TIMUR R. SAMATOV, ${ }^{2}$ REINHARD LÜHRMANN, ${ }^{2,4}$ \\ and ADEGBOYEGA K. OYELERE ${ }^{1,3,4}$ \\ ${ }^{1}$ School of Chemistry and Biochemistry, Georgia Institute of Technology, Atlanta, Georgia 30332-0400, USA \\ ${ }^{2}$ Department of Cellular Biochemistry, Max Planck Institute for Biophysical Chemistry, D-37077 Göttingen, Germany \\ ${ }^{3}$ Parker H. Petit Institute for Bioengineering and Bioscience, Georgia Institute of Technology, Atlanta, Georgia 30332-0400, USA
}

\begin{abstract}
The removal of intervening sequences (introns) from a primary RNA transcript is catalyzed by the spliceosome, a large ribonucleoprotein complex. At the start of each splicing cycle, the spliceosome assembles anew in a sequentially ordered manner on the pre-mRNA intron to be removed. We describe here the identification of a series of naphthalen-2-yl hydroxamate compounds that inhibit pre-mRNA splicing in vitro with mid- to high-micromolar values of $\mathrm{IC}_{50}$. These hydroxamates stall spliceosome assembly at the A complex stage. A structure-activity analysis of lead compounds revealed three pharmacophores that are essential for splicing inhibition. Specifically, a hydroxamate as a zinc-binding group and a 6-methoxynaphthalene cap group are both critical, and a linker chain comprising eight to nine methylene groups is also important, for the specific binding to the docking site of a target protein molecule and precise positioning of the zinc binding group. As we found no correlation between the inhibition patterns of known histone deacetylases on the one hand and pre-mRNA splicing on the other, we conclude that these compounds may function through the inhibition of the activities of other, at present, unknown spliceosomeassociated zinc metalloprotein(s).
\end{abstract}

Keywords: pre-mRNA splicing; spliceosome assembly; inhibitors; zinc chelator

\section{INTRODUCTION}

The removal of introns from a primary RNA transcript is catalyzed by a large ribonucleoprotein (RNP) complex termed the spliceosome. This is a highly complex and dynamic RNP machine. It is composed of the five snRNPs U1, U2, $\mathrm{U} 4, \mathrm{U} 5$, and U6 and a large number of non-snRNP proteins (Wahl et al. 2009). Spliceosomes assemble in a stepwise manner and thus pass through a series of distinct complexes. Initially, the U1 and U2 snRNPs bind the pre-mRNA, forming the A complex. Subsequently, the U4/U6.U5 trisnRNP associates, and the precatalytic B complex is generated. After major rearrangements resulting in the displacement of $\mathrm{U} 1$ and $\mathrm{U} 4$, the activated spliceosome $\left(\mathrm{B}^{\text {act }}\right)$ is formed, followed by additional restructuring and catalysis of step 1 of splicing. This involves cleavage at the $5^{\prime}$ splice site of the pre-mRNA and the ligation of the $5^{\prime}$ end of the intron to

${ }^{4}$ Corresponding authors

E-mail aoyelere@gatech.edu

E-mail reinhard.luehrmann@mpi-bpc.mpg.de

Article published online ahead of print. Article and publication date are at http://www.rnajournal.org/cgi/doi/10.1261/rna.034819.112. the so-called branch site to form a lariat-like structure. This leads to formation of the spliceosomal C complex, which catalyzes step 2 of splicing, during which the intron is excised and the exons are ligated together to form mRNA. Subsequently, the spliceosome dissociates, and the snRNPs are recycled for additional rounds of splicing.

Aberrant pre-mRNA splicing is associated with many human diseases, including cancer, and neurodegenerative and autoimmune diseases, making the spliceosome a highly attractive drug target (Tazi et al. 2005b). Small molecules arresting spliceosome assembly at defined points would also be of great use for the detailed investigation of the structure and function of the spliceosome. To date, only a limited number of small-molecule inhibitors of pre-mRNA splicing have been identified. These include antibiotics (erythromycin, Cl-tetracycline, and streptomycin) (Hertweck et al. 2002), a biflavanoid (isoginkgetin) (O’Brien et al. 2008), inhibitors of the kinase activity of topoisomerase I (Pilch et al. 2001; Tazi et al. 2005a), antitumor drugs targeting the U2 snRNP-i.e., spliceostatin A (Kaida et al. 2007) and pladienolide (Kotake et al. 2007) —selected inhibitors of histone deacetylases and histone acetyltransferases (Kuhn et al. 2009), lichen secondary metabolites (Samatov et al. 
2012), and 1,4-naphthoquinones and 1,4-heterocyclic quinones with known anticancer activity (Berg et al. 2012). The specific spliceosome targets of these compounds have been identified in only a few cases. The lack of a clear understanding of their mechanism of action may be partly due to the structural complexities of many of these compounds.

Several spliceosome-associated proteins possess potential enzymatic activities whose function in the splicing reaction remains unclear (Hartmuth et al. 2002; Rappsilber et al. 2002; Zhou et al. 2002; Jurica and Moore 2003; Deckert et al. 2006). For example, numerous peptidyl-prolyl isomerases have been found, even though it is not clear whether their isomerase activity is required at all, or whether their domains are involved in protein-protein interactions. In addition, many proteins exhibit zinc-binding motifs, suggesting that zinc ions may have functional and/or structural roles in splicing (Rappsilber et al. 2002; Zhou et al. 2002; Jurica and Moore 2003; Agafonov et al. 2011). Additionally, the activity of histone deacetylases (HDACs), which are classical zinc metalloproteases, has been shown to be important for splicing catalysis, although their precise functions in the splicing process are not clear (Hnilicová et al. 2011). In fact, zinc depletion by the chelator 1,10-phenanthroline (1,10-phe) has been shown to inhibit the second step of splicing (Shomron et al. 2002). It has been demonstrated that specific zinc-chelating agents that perturb the acetylation state of proteins (through inhibition of HDACs activity) block the splicing cycle (Kuhn et al. 2009). However, the exact relationship between zinc chelation, protein acetylation state, and splicing inhibition is not clear, as only a limited set of HDAC inhibitors (HDACis) was screened. In the present work, we sought to clarify this relationship by screening a HDACi library that was structurally more diverse (Chen et al. 2008; Canzoneri et al. 2009; Oyelere et al. 2009; Mwakwari et al. 2010a,b; Patil et al. 2010). We report here the elucidation of unique molecular features that confer splicing inhibition upon zinc-chelating agents with HDAC inhibition activity. Native gel analyses of splicing reactions revealed that these agents inhibit spliceosome assembly at an early stage, with the formation/stability even of the A complex compromised. The absence of any correlation between HDAC and the splicing-inhibition activities of these compounds suggests that the primary target(s) involved in splicing inhibition are not HDACs. However, the existence of certain similarities does suggest possible structural resemblance(s) in the docking site and a common involvement of zinc ions.

\section{RESULTS AND DISCUSSION}

\section{Screening of structurally diverse HDACis for splicing inhibition activity}

Earlier work has demonstrated the presence of HDACs in purified populations of spliceosomes (Rappsilber et al.
2002; Zhou et al. 2002; Gunderson et al. 2011), and based on this information, we previously investigated the splicing inhibition activity of selected HDAC inhibitors (Kuhn et al. 2009). These HDACis inhibited splicing with sub- to lowmillimolar $\mathrm{IC}_{50}$ values (the concentration giving 50\% inhibition). However, there was no clear evidence linking the effects of these compounds on splicing with their actual inhibition of HDACs, especially as their $\mathrm{IC}_{50}$ values in splicing were found to be several orders of magnitude higher than the reported values for HDAC inhibition. HDACs have 18 known isoforms, organized into four different classes. Classes I, II, and IV depend on a catalytic zinc ion and differ in their cellular location, while Class III HDACs require $\mathrm{NAD}+$ (Ropero and Esteller 2007). The prototypic pharmacophore for HDACi consists of three distinct structural motifs: a recognition cap group, a hydrophobic linker, and a zinc-binding group (Fig. 1; Miller et al. 2003; Mwakwari et al. 2010b). The recognition cap group moieties of HDACis interact with amino acid residues on the surface of HDACs and present excellent opportunities for the selective modulation of their biological activities (Mwakwari et al. 2010b). We surmised that profiling the splicing inhibition activities of HDACis that differ with respect to their three distinct structural motifs might help us to discern possible links between HDAC inhibition and inhibitory effects on the splicing reaction. To this end, we first screened a small (63-member), yet structurally diverse HDACi library (see Supplemental Table S1 for the structures) at $100 \mu \mathrm{M}$ using a conventional in vitro splicing assay. The HDAC inhibition activity of compounds in the screened library against HDAC1 and HeLa cell nuclear extract HDACs ranges from single digit- to mid-nanomolar (Chen et al. 2008; Canzoneri et al. 2009; Oyelere et al. 2009; Mwakwari et al. 2010a; Patil et al. 2010). Despite their potency, these HDACis did not broadly inhibit splicing. We identified only two compounds-6-methoxynaphthalen-2-yl hydroxamates 24 and 25 that noticeably inhibit splicing at $100 \mu \mathrm{M}$ (Fig. 2). The structures of these compounds are almost identical, differing only in the length of a hydrophobic linker, six methylene groups for 24 and seven for 25. More detailed investigation revealed that these compounds inhibit pre-mRNA splicing with the same efficiency (Fig. 2B). Complete inhibition of splicing was observed at $150 \mu \mathrm{M}$

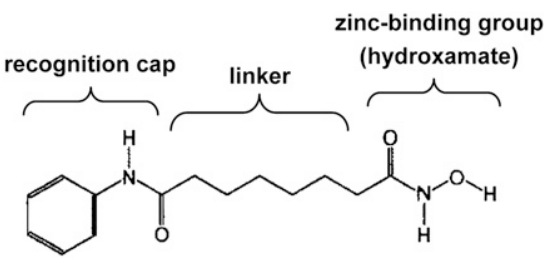

FIGURE 1. The prototypic pharmacophore for histone deacetylase inhibitors (here, SAHA), which typically is comprised of three distinct structural motifs: a recognition cap group, a hydrophilic linker, and a zinc-binding group. 

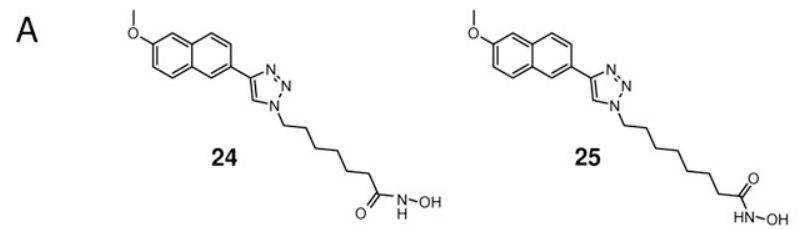

B

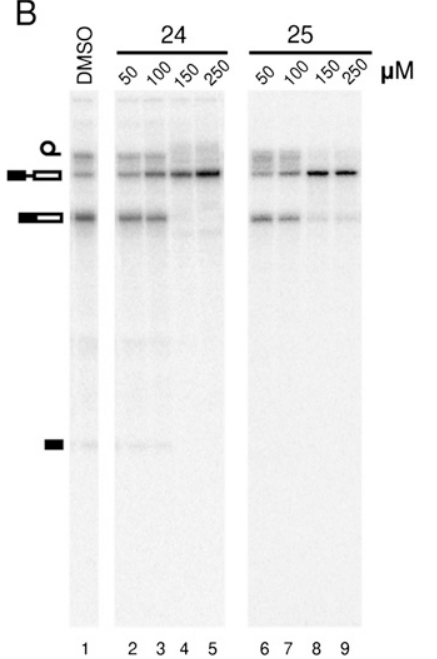

C

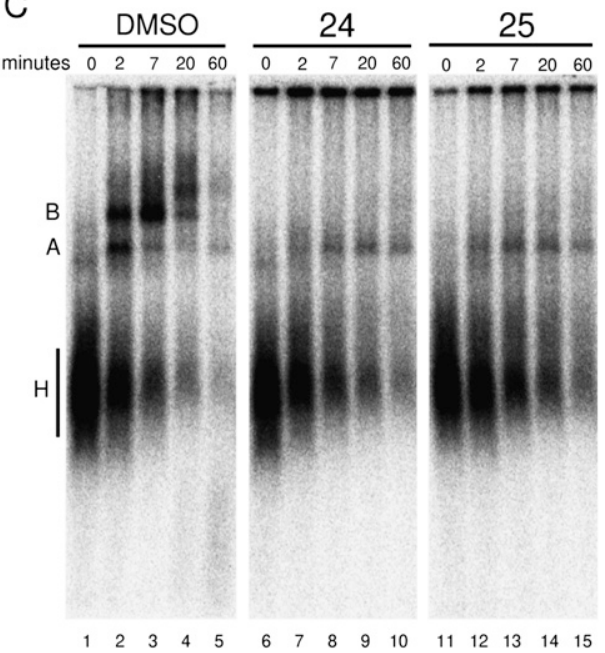

FIGURE 2. Hit compounds 24 and 25 inhibit pre-mRNA splicing in vitro and lead to an accumulation of spliceosome assembly intermediates. (A) Structures of the compounds. $(B)$ Increasing concentrations of compounds $\mathbf{2 4}$ and $\mathbf{2 5}$ were tested for their effect on the splicing of ${ }^{32} \mathrm{P}$-labeled MINX pre-mRNA. After splicing, the radiolabeled RNA was analyzed by denaturing PAGE followed by autoradiography. The left-most lane shows the DMSO control experiment. Compound numbers are shown at the top of the panel, and drug concentrations tested are shown immediately below the compound numbers. The positions of lariat-intron, pre-mRNA, fully spliced mRNA, and $5^{\prime}$ exon (top to bottom) are indicated on the left. $(C)$ Formation of splicing complex on ${ }^{32} \mathrm{P}$-labeled MINX pre-mRNA in the presence of $250 \mu \mathrm{M}$ of the respective compounds. Reactions were stopped at the time points indicated, and the products were analyzed on a native agarose gel. Bands were visualized by phosphor imaging. The positions of the splicing complexes $(\mathrm{H}, \mathrm{A}$, and $\mathrm{B})$ are indicated.

(Fig. 2B, lanes 4,8 ), with an $\mathrm{IC}_{50}$ value of $\sim 130 \mu \mathrm{M}$ for both compounds (Table 1).

To determine at which stage splicing complex formation is inhibited, we performed a splicing time course experiment. The spliceosomal complexes formed were analyzed by native agarose gel electrophoresis. After 2 min of splicing, predominantly $\mathrm{A}$ and $\mathrm{B}$ complexes were visible in the DMSO control (Fig. 2C, lane 2). After 7 min, most A complexes had been converted into B complexes, which were, in turn, converted into later complexes ( ${ }^{\text {act }}, C$ ) after 20 min. After 60 min, only small amounts of the $A, B^{\text {act }}$, and $C$ were still visible (lanes 3-5). In the presence of $250 \mu \mathrm{M}$ of compound 24 or 25 , the kinetics of splicing complex assembly appeared similar to each other but differed dramatically from those in the DMSO control (Fig. 2C, lanes 6-15). Mainly A complexes accumulated at all of the time points analyzed. Thus, B complex formation is inhibited, indicating that one or more protein factors required for it are inactivated by these compounds. In addition, the amount of stalled A complexes was significantly lower than in the DMSO control reaction (cf. the 2-min time point, lane 2).
This indicates that the formation and/or stability of spliceosomal A complexes is compromised by these HDACis. These data imply that potential targets of these compounds also include proteins involved in the assembly of the A complex. Remarkably, compound $\mathbf{2 4}$ has an HDAC inhibition activity 15 times higher than that of compound 25 (Table 1; Patil et al. 2010), yet both compounds stalled spliceosome assembly to approximately the same extent. Another intriguing observation is the fact that compound 9 (Supplemental Table S1), an analog of $\mathbf{2 4}$ with a single methylene chain deletion and a more than eightfold stronger HDAC inhibition than 24 (Chen et al. 2008), was not identified as a splicing inhibitor in the primary screen. These data, together with the fact that only two structurally related compounds have been identified among the 63 diverse potent HDACis, suggest that the target(s) of these compounds responsible for splicing inhibition may not be HDACs.

\section{Structure-activity relationship (SAR) of splicing inhibition}

The screening of the HDACi library (Oyelere et al. 2009; Patil et al. 2010) for splicing inhibition identified 6-methoxynaphthalen-2-yl hydroxamates 24 and 25 as small molecules that inhibit spliceosome assembly at an early stage, to about the same extent, with $\mathrm{IC}_{50}$ values close to $130 \mu \mathrm{M}$ (Table 1 ). These data provided an initial indication that the inhibition of splicing may not be due to the targeting of HDACs. To investigate this question further, we carried out a detailed structure-activity analysis of these compounds. We synthesized a series of structural analogs of compounds 24 and 25 and tested their effect on the in vitro splicing of ${ }^{32} \mathrm{P}$-labeled MINX premRNA, as well as their HDAC inhibitory activity against representative class I and class II HDAC isoforms-HDAC1, HDAC6, and HDAC8. First, we investigated the length of a hydrophobic linker between the recognition cap and zinc-binding groups. Compounds 24 and 25 have 6- and 7-methylene chain linkers, respectively (Table 1). A shorter version present in the initial compound collection, with five methylene groups, was filtered out as inactive against splicing (compound 9) (Supplemental Table S1). We thus experimented with introducing longer linkers. Indeed, single- (compound 67a), as well as double- (compound 67b) methylene chain extensions significantly increased 
TABLE 1. Structure-activity relationships of the splicing inhibition activities of 6-methoxynaphthalen-2-yl hydroxamates

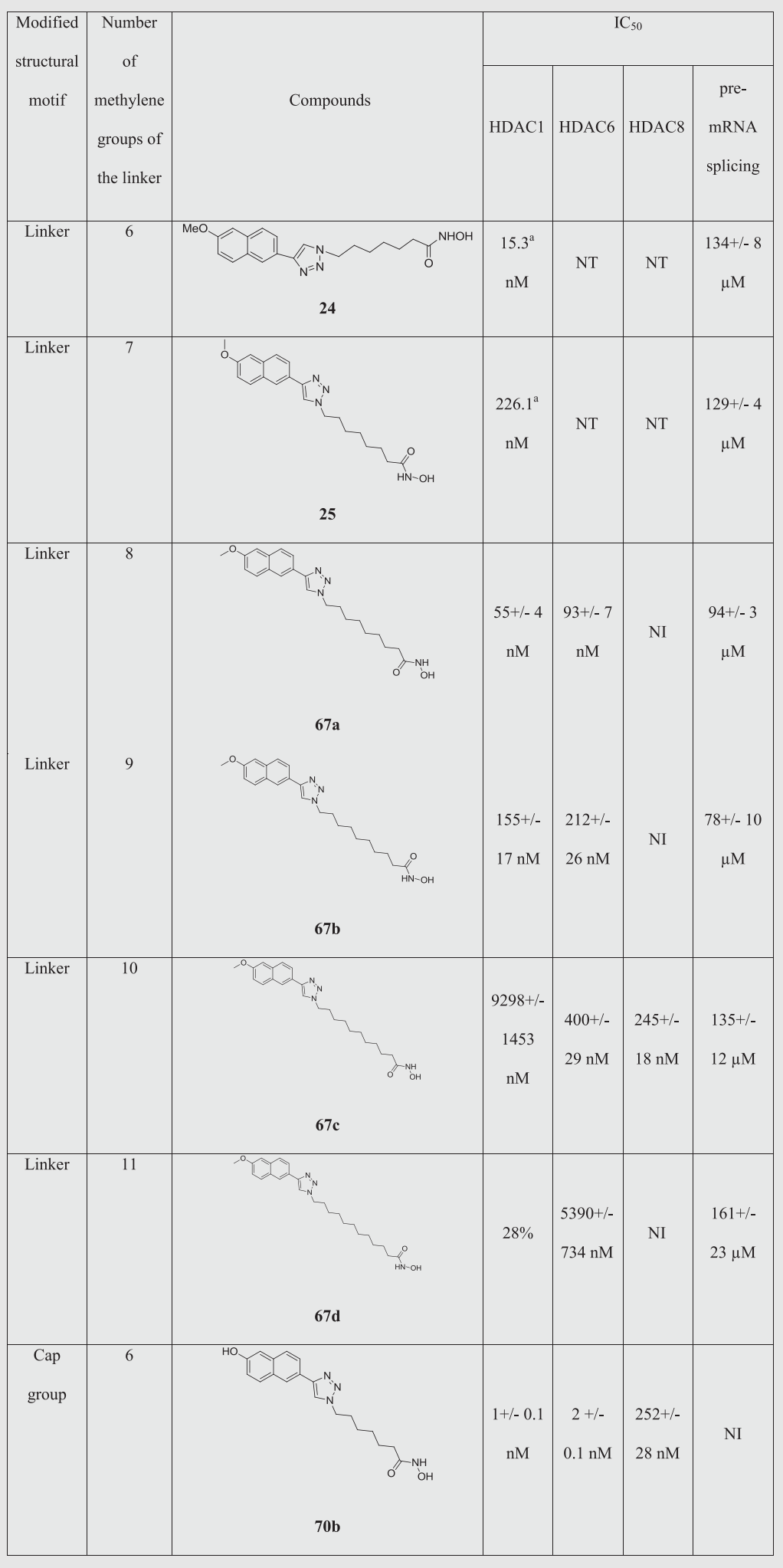

(continued) splicing inhibition potency (Table 1). Further increase in the length resulted in compounds that were less active (i.e., 67c) or slightly less potent (i.e., 67d), although these were still almost as potent as the lead compounds $\mathbf{2 4}$ and $\mathbf{2 5}$. Thus, there is a correlation between the anti-splicing activity and the length of the linker, with an optimum number of methylene groups of eight and nine. As for the HDAC inhibitory activity, compounds 67a and 67b inhibited HDAC1 and HDAC6 with mid-nanomolar $\mathrm{IC}_{50} \mathrm{~s}$ and were completely inactive against HDAC8, while $67 \mathrm{c}$ potently inhibited HDAC6 and HDAC8 and was almost inactive against HDAC1. Interestingly, compound $67 \mathrm{~d}$ had the poorest HDAC inhibitory activity; it was found to be inactive against HDAC1 and HDAC6 and weakly active against HDAC8, yet it showed significant inhibition of splicing.

Another structural motif of the pharmacophore that we investigated was the naphthalene cap group. The substitution of the 6-methoxy moiety by a protic electron-donating group such as $\mathrm{OH}$ or $\mathrm{NH}_{2}$ was detrimental to the function of the compounds, as these changes abolished splicing inhibitory activity (Table 1 ; cf. 70b,70c and 24; 70d and 25). In contrast, compounds 70b, 70c, and 70d were found to be broadly active against the HDAC isoforms tested, with singledigit nanomolar to mid-nanomolar $\mathrm{IC}_{50} \mathrm{~s}$ against HDAC1 and HDAC6. The observation that there is no correlation between anti-HDAC and anti-splicing activities of these molecules supports the suggestion that the targets of these compounds in splicing are not HDACs. In addition, these data suggest that the naphthalene cap group needs to be specifically recognized by the target protein(s). It is noteworthy that compounds 74a and 74b-containing a single methylene extension of the naphthalene cap 6-ether moiety compared with $\mathbf{2 5}$ and 67b, respectively- possess almost the same splicing inhibitory activity as the initial compounds.

To investigate the role of zinc chelation in the splicing-inhibitory activity of these naphthalene-2-yl hydroxamates, we synthesized methyl esters $\mathbf{8 0}$ and $\mathbf{8 1}$ 
TABLE 1. Continued

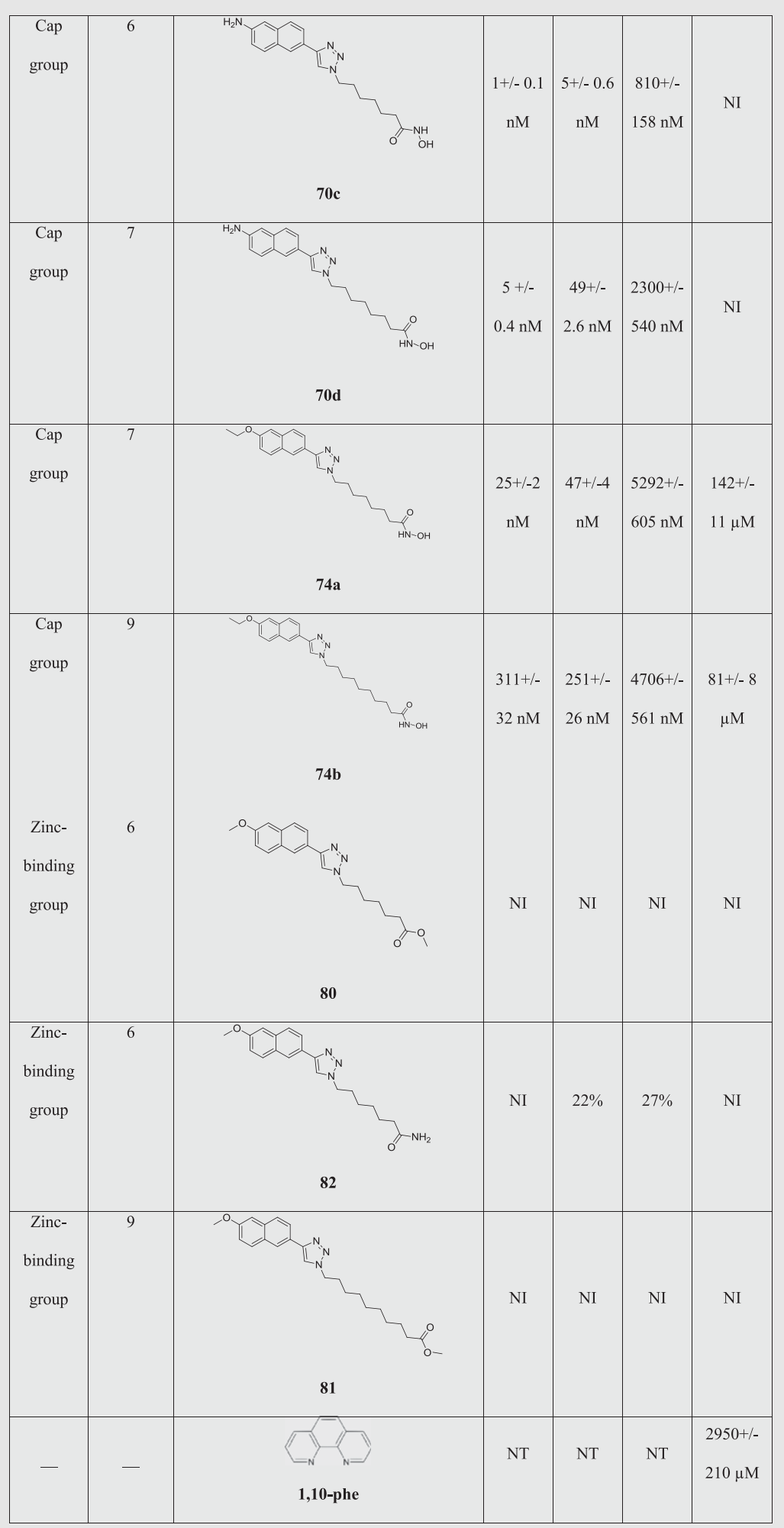

(NT) not tested, (NI) no significant inhibition (below 20\%). \% HDAC inhibition activities of the compounds at $10 \mu \mathrm{M}$ are shown if the $\mathrm{IC}_{50}$ was above $10 \mu \mathrm{M}$.

${ }^{a}$ Cited from references (Chen et al. 2008; Patil et al. 2010) —activities against HeLa nuclear extract (HDAC 1 and 2). and carboxamide 82. These compounds are the derivatives of the hydroxamates 24 and 67b. As expected, all of these nonhydroxamate analogs lacked HDAC inhibitory activity. Significantly, they also failed to inhibit splicing in vitro (Table 1). These results indicate that zinc coordination is important for both antiHDAC and anti-splicing activities. An add-back experiment was performed to test whether the inhibition is, indeed, due to the chelation of zinc (Fig. 3). The indicated concentrations of $\mathrm{ZnCl}_{2}$ were added at the beginning of the splicing reaction (addition time 0 min, odd lanes) or after $1 \mathrm{~h}$ incubation (addition time $60 \mathrm{~min}$, even lanes), followed by another 60-min incubation under splicing conditions. The addition of 30 and $100 \mu \mathrm{M}$ $\mathrm{ZnCl}_{2}$ to the control reaction with DMSO had little effect on splicing, although the pre-mRNA substrate appeared to be slightly stabilized in some cases (lanes 1-6). The splicing reaction was substantially inhibited in the presence of $100 \mu \mathrm{M} \mathrm{67b}$, one of the most potent compounds described here (lanes 7,8). Addition of $30 \mu \mathrm{M} \mathrm{ZnCl} 2$ before initiation of the splicing reaction did not reverse inhibition by $67 \mathrm{~b}$, whereas addition of $100 \mu \mathrm{M} \mathrm{ZnCl}$ restored splicing efficiency to near control levels (lanes 9,11). Addition of $100 \mu \mathrm{M} \mathrm{ZnCl}_{2}$ also led to a general increase in the amount of the splicing substrate, but the observed increase in the splicing products is not due solely to this apparent stabilization effect. Interestingly, addition of $\mathrm{ZnCl}_{2}$ to the inhibited splicing reaction $1 \mathrm{~h}$ later had no effect (lanes $10,12)$. These data suggest that compound $67 \mathrm{~b}$ irreversibly inhibits splicing; once it binds to its target protein and chelates its zinc ion, the inhibitory effect, which could potentially involve a structural change in the targeted protein, can no longer be reversed by exogeneously added zinc ions. In contrast, allowing compound $67 \mathrm{~b}$ to bind zinc prior to interacting with its target protein neutralizes its inhibitory effect, presumably by preventing $67 \mathrm{~b}$ from removing the zinc that is normally bound by its target protein. This result confirms the principal role of zinc chelation in the 


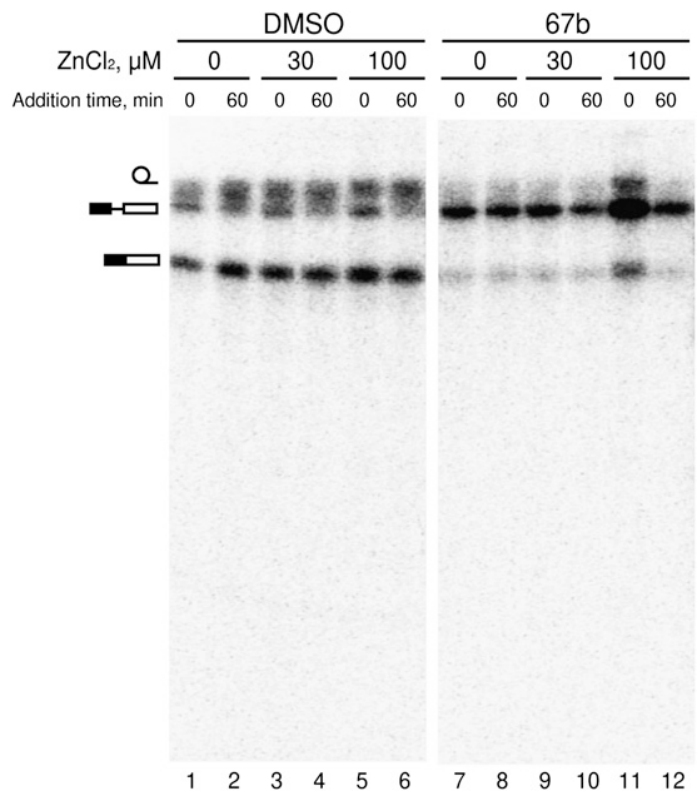

FIGURE 3. Relieving the inhibitory effect of the compound $\mathbf{6 7 b}$. Radiolabeled MINX pre-mRNA was incubated in nuclear extract under standard splicing conditions in the presence of DMSO (lanes 1-6) or compound $\mathbf{6 7 b}$ (lanes 7-12) at the semi-inhibitory concentration of $100 \mu \mathrm{M}$, and the indicated concentration of $\mathrm{ZnCl}_{2}$ that was added at the indicated reaction time points. After splicing, the radiolabeled RNA was analyzed by denaturing PAGE followed by autoradiography. The positions of lariat-intron, pre-mRNA, and fully spliced mRNA (top to bottom) are indicated on the left.

mechanism of action of the compounds described. However, one should note the dramatic difference between the effects observed here, and those of the zinc chelation by 1,10-phe, which requires millimolar concentrations and results in the reversible inhibition of step 2 of splicing (Table 1; Shomron et al. 2002).

\section{CONCLUSIONS}

All three structural motifs of the pharmacophore for HDACis exhibit a synergistic activity, as the cap group and linker are both important for the specific binding to the docking site of the target protein molecule and precise positioning of the zinc-binding group for effective zinc chelation. The SAR analysis of the compounds identified that inhibit splicing reveals that all three groups are important for splicing inhibition activity, though to different degrees. The intact zinc-binding group is absolutely essential, and the naphthalene cap group is also important; the hydrophobic linker has a more pronounced length restriction in that linkers with eight and nine methylene groups confer the highest activity upon the compounds. Taken together, our data suggest that splicing inhibition involves not only the interaction of the inhibitor with one or more splicing factors but also that its zinc binding group is positioned close to the zinc binding group of the target protein, leading to chelation of its zinc. They furthermore suggest that the target proteins are not HDACs. In fact, there are a number of spliceosomal proteins that contain zinc finger motifs and associate with different complexes during the spliceosome assembly pathway (Rappsilber et al. 2002; Zhou et al. 2002; Jurica and Moore 2003; Bessonov et al. 2008, 2010; Agafonov et al. 2011). Their detailed biochemical function is not yet clear, and they could well be targets of the compounds presented here. Our future work will include the affinity labeling of these compounds which, it is hoped, will aid the identification of the target(s) in the spliceosome and thus provide insight into their mechanism of splicing inhibition.

\section{MATERIALS AND METHODS}

\section{HDAC inhibition assay}

In vitro HDAC inhibition was assayed using the HDAC Fluorimetric Assay/Drug Discovery Kit as previously described (Chen et al. 2008; Oyelere et al. 2009; Mwakwari et al. 2010a). Briefly, $15 \mu \mathrm{L}$ of HeLa nuclear extract was mixed with $5 \mu \mathrm{L}$ of $10 \times$ compound and $5 \mu \mathrm{L}$ of assay buffer. Fluorogenic substrate $(25 \mu \mathrm{L})$ was added, and the reaction was allowed to proceed for $15 \mathrm{~min}$ at room temperature and then stopped by addition of a developer containing TSA. Fluorescence was monitored after $15 \mathrm{~min}$ at excitation and emission wavelengths of 360 and $460 \mathrm{~nm}$, respectively. $\mathrm{IC}_{50}$ values were determined using logit plots. Assays of HDAC1, HDAC6, and HDAC8 activity were performed according to the manufacturer's instructions.

\section{Splicing substrates, reactions, and spliceosome complex analysis}

Uniformly ${ }^{32} \mathrm{P}$-labeled, $\mathrm{m}^{7} \mathrm{G}\left(5^{\prime}\right) \mathrm{ppp}\left(5^{\prime}\right) \mathrm{G}$-capped MINX premRNA was synthesized in vitro by $\mathrm{T} 7$ runoff transcription. Splicing reactions contained $30 \%(\mathrm{v} / \mathrm{v}) \mathrm{HeLa}$ nuclear extract in buffer D (20 mM HEPES-KOH at pH 7.9, $100 \mathrm{mM} \mathrm{KCl,} 1.5 \mathrm{mM}$ $\mathrm{MgCl}_{2}, 0.2 \mathrm{mM}$ EDTA, 20\% [v/v] glycerol, $0.5 \mathrm{mM}$ DTT, $0.5 \mathrm{mM}$ PMSF), $25 \mathrm{mM} \mathrm{KCl}, 3 \mathrm{mM} \mathrm{MgCl}$, $20 \mathrm{mM}$ creatine phosphate, $2 \mathrm{mM}$ ATP, $3 \mathrm{nM}^{32} \mathrm{P}$-labeled pre-mRNA, 2.5\% (v/v) DMSO, and the indicated concentration of the chemicals tested for their effect on splicing. For the analysis of the splicing products, the reactions were stopped after a $60-\mathrm{min}$ incubation at $30^{\circ} \mathrm{C}$. RNA was isolated by proteinase $\mathrm{K}$ treatment, phenol extraction, and ethanol precipitation, and then separated by denaturing polyacrylamide gel electrophoresis on a $7 \mathrm{M}$ urea, $14 \%(\mathrm{w} / \mathrm{v})$ polyacrylamide gel and visualized by phosphor imaging (Typhoon 8600, GE Healthcare). For the analysis of spliceosomal complexes, $10 \mu \mathrm{L}$ of the splicing reaction were added to $2.5 \mu \mathrm{L}$ of loading buffer $(1 \times \mathrm{TBE}, 30 \%$ [v/v] glycerol, $1.25 \mathrm{mg} / \mathrm{mL}$ heparin) at the time points indicated, and the mixture was then placed on ice. Complexes were separated on $1.5 \%(\mathrm{w} / \mathrm{v})$ agarose gels and visualized by phosphor imaging.

\section{SUPPLEMENTAL MATERIAL}

Supplemental material is available for this article. 


\section{ACKNOWLEDGMENTS}

We thank Bob Chen, Sandra Mwakwari, and William Guerrant for their contribution to the library used in the original screening assay. This work was supported by NIH Grant R01 A131217 and a grant from the Deutsche Forschungsgemeinschaft (FOR 806) to R.L.

Received June 8, 2012; accepted June 11, 2012.

\section{REFERENCES}

Agafonov DE, Deckert J, Wolf E, Odenwälder P, Bessonov S, Will CL, Urlaub H, Lührmann R. 2011. Semiquantitative proteomic analysis of the human spliceosome via a novel two-dimensional gel electrophoresis method. Mol Cell Biol 31: 2667-2682.

Berg MG, Wan L, Younis I, Diem MD, Soo M, Wang C, Dreyfuss G. 2012. A quantitative high-throughput in vitro splicing assay identifies inhibitors of spliceosome catalysis. Mol Cell Biol 32: 1271-1278.

Bessonov S, Anokhina M, Will CL, Urlaub H, Lührmann R. 2008. Isolation of an active step I spliceosome and composition of its RNP core. Nature 452: 846-850.

Bessonov S, Anokhina M, Krasauskas A, Golas MM, Sander B, Will CL, Urlaub H, Stark H, Lührmann R. 2010. Characterization of purified human $\mathrm{B}^{\text {act }}$ spliceosomal complexes reveals compositional and morphological changes during spliceosome activation and first step catalysis. RNA 16: 2384-2403.

Canzoneri JC, Chen P, Oyelere AK. 2009. Design and synthesis of novel histone deacetylase inhibitor derived from nuclear localization signal peptide. Bioorg Med Chem Lett 19: 6588-6590.

Chen P, Patil V, Guerrant W, Green P, Oyelere AK. 2008. Synthesis and structure-activity relationship of histone deacetylase (HDAC) inhibitors with triazole-linked cap group. Bioorg Med Chem 16: 4839-4853.

Deckert J, Hartmuth K, Boehringer D, Behzadnia N, Will CL, Kastner B, Stark H, Urlaub H, Lührmann R. 2006. Protein composition and electron microscopy structure of affinity-purified human spliceosomal B complexes isolated under physiological conditions. Mol Cell Biol 26: 5528-5543.

Gunderson FQ, Merkhofer EC, Johnson TL. 2011. Dynamic histone acetylation is critical for cotranscriptional spliceosome assembly and spliceosomal rearrangements. Proc Natl Acad Sci 108: 2004-2009.

Hartmuth K, Urlaub H, Vornlocher HP, Will CL, Gentzel M, Wilm M, Lührmann R. 2002. Protein composition of human prespliceosomes isolated by a tobramycin affinity-selection method. Proc Natl Acad Sci 99: 16719-16724.

Hertweck M, Hiller R, Mueller MW. 2002. Inhibition of nuclear premRNA splicing by antibiotics in vitro. Eur J Biochem 269: 175-183.

Hnilicová J, Hozeifi S, Dušková E, Icha J, Tománková T, Staněk D. 2011. Histone deacetylase activity modulates alternative splicing. PLoS ONE 6: e16727. doi: 10.1371/journal.pone.0016727.

Jurica MS, Moore MJ. 2003. Pre-mRNA splicing: Awash in a sea of proteins. Mol Cell 12: 5-14.

Kaida D, Motoyoshi H, Tashiro E, Nojima T, Hagiwara M, Ishigami K, Watanabe H, Kitahara T, Yoshida T, Nakajima H, et al. 2007.
Spliceostatin A targets SF3b and inhibits both splicing and nuclear retention of pre-mRNA. Nat Chem Biol 3: 576-583.

Kotake Y, Sagane K, Owa T, Mimori-Kiyosue Y, Shimizu H, Uesugi M, Ishihama Y, Iwata M, Mizui Y. 2007. Splicing factor SF3b as a target of the antitumor natural product pladienolide. Nat Chem Biol 3: 570-575.

Kuhn AN, van Santen MA, Schwienhorst A, Urlaub H, Lührmann R. 2009. Stalling of spliceosome assembly at distinct stages by smallmolecule inhibitors of protein acetylation and deacetylation. RNA 15: 153-175.

Miller TA, Witter DJ, Belvedere S. 2003. Histone deacetylase inhibitors. J Med Chem 46: 5097-5116.

Mwakwari SC, Guerrant W, Patil V, Khan SI, Tekwani BL, Gurard-Levin ZA, Mrksich M, Oyelere AK. 2010a. Non-peptide macrocyclic histone deacetylase inhibitors derived from tricyclic ketolide skeleton. J Med Chem 53: 6100-6111.

Mwakwari SC, Patil V, Guerrant W, Oyelere AK. 2010b. Macrocyclic histone deacetylase inhibitors. Curr Top Med Chem 10: 1423-1440.

O’Brien K, Matlin AJ, Lowell AM, Moore MJ. 2008. The biflavonoid isoginkgetin is a general inhibitor of pre-mRNA splicing. $J$ Biol Chem 283: 33147-33154.

Oyelere AK, Chen P, Guerrant W, Mwakwari SC, Hood R, Zhang Y, Fan Y. 2009. Non-peptide macrocyclic histone deacetylase inhibitors. J Med Chem 52: 456-468.

Patil V, Guerrant W, Chen P, Gryder B, Benicewicz DB, Khan SI, Tekwani BL, Oyelere AK. 2010. Antimalarial and antileishmanial activities of histone deacetylase inhibitors with triazole-linked cap group. Bioorg Med Chem 18: 415-425.

Pilch B, Allemand E, Facompré M, Bailly C, Riou JF, Soret J, Tazi J. 2001. Specific inhibition of serine- and arginine-rich splicing factors phosphorylation, spliceosome assembly, and splicing by the antitumor drug NB-506. Cancer Res 61: 6876-6884.

Rappsilber J, Ryder U, Lamond AI, Mann M. 2002. Large-scale proteomic analysis of the human spliceosome. Genome Res 12: $1231-1245$.

Ropero S, Esteller M. 2007. The role of histone deacetylases (HDACs) in human cancer. Mol Oncol 1: 19-25.

Samatov TR, Wolf A, Odenwälder P, Bessonov S, Deraeve C, Bon RS, Waldmann H, Lührmann R. 2012. Psoromic acid derivatives: A new family of small-molecule pre-mRNA splicing inhibitors discovered by a stage-specific high-throughput in vitro splicing assay. ChemBioChem 13: 640-644.

Shomron N, Malca H, Vig I, Ast G. 2002. Reversible inhibition of the second step of splicing suggests a possible role of zinc in the second step of splicing. Nucleic Acids Res 30: 4127-4137.

Tazi J, Bakkour N, Soret J, Zekri L, Hazra B, Laine W, Baldeyrou B, Lansiaux A, Bailly C. 2005a. Selective inhibition of topoisomerase I and various steps of spliceosome assembly by diospyrin derivatives. Mol Pharmacol 67: 1186-1194.

Tazi J, Durand S, Jeanteur P. 2005b. The spliceosome: A novel multi-faceted target for therapy. Trends Biochem Sci 30: 469478.

Wahl MC, Will CL, Lührmann R. 2009. The spliceosome: Design principles of a dynamic RNP machine. Cell 136: 701-718.

Zhou Z, Licklider LJ, Gygi SP, Reed R. 2002. Comprehensive proteomic analysis of the human spliceosome. Nature 419: 182185. 

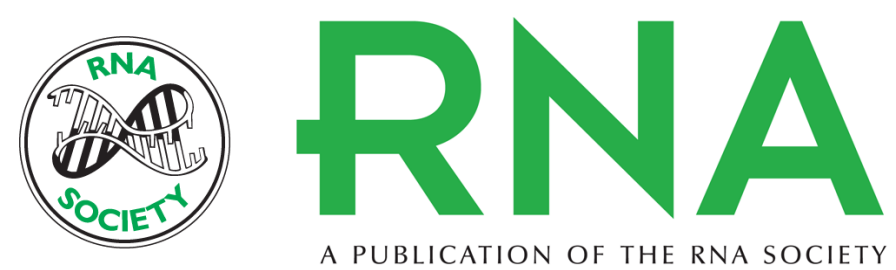

\section{Molecular architecture of zinc chelating small molecules that inhibit spliceosome assembly at an early stage}

Vishal Patil, Josh C. Canzoneri, Timur R. Samatov, et al.

RNA 2012 18: 1605-1611 originally published online July 25, 2012

Access the most recent version at doi:10.1261/rna.034819.112

Supplemental http://rnajournal.cshlp.org/content/suppl/2012/06/26/rna.034819.112.DC1
Material

References This article cites 30 articles, 11 of which can be accessed free at: http://rnajournal.cshlp.org/content/18/9/1605.full.html\#ref-list-1

License

Email Alerting Receive free email alerts when new articles cite this article - sign up in the box at the Service top right corner of the article or click here. 